\title{
Sputum induction as a research tool for sampling the airways of subjects with cystic fibrosis
}

\author{
N R Henig, M R Tonelli, M V Pier, J L Burns, M L Aitken
} \section{) and bronchoalveolar lavage (BAL). A ) and bronchoalveolar lavage (BAL). A y was undertaken to evaluate the

$$
\text { cystic fibrosis (CF). }
$$$$
\text { safety of SI and to assess if it might be an }
$$ Methods-The safety of the procedure was
examined and sample volume, cell counts, mined and sample volume, cell counts, culture results obtained by SI, spontane-
ous ES, and fibreoptic bronchoscopy were pared in 10 adults with CF. ilts-SI was well tolerated and was erred to BAL by all subjects. The (SE) sample volume obtained by SI an (SE) sample volume obtained by SI
significantly greater than ES $(6.74$ (1.46) $\mathrm{ml} v 1.85(0.33) \mathrm{ml}, \mathrm{p}=0.005)$.
There was no significant difference in the
number of cells per $\mathrm{ml}$ of sample col- was no significant difference in the
ber of cells per $\mathrm{ml}$ of sample col- There was a difference in the mean d. There was a difference in the mean
percentage of non-epithelial, non- mous cells collected (67 (28)\%, 86 $\%$, and 99 (1)\% for ES, SI, and BAL, 0.03 and $p=0.006$, respectively).} squamous cells) from all collection methods were similar (mean (SD) 84 (9)\%, 87 (7)\%, and 88 (11)\% polymorphonuclear cells for ES, SI, and BAL, respectively). The concentrations of interleukin (IL) -8 and tumour necrosis factor (TNF)- $\alpha$ were the same in all three samples when corrected for dilution using urea concentration. The test specific detection rate for recovery of bacteriological pathogens was $79 \%$ for SI, $76 \%$ for $\mathrm{ES}$, and $73 \%$ for $\mathrm{BAL}$. Conclusion-SI offers safety advantages over BAL and may be a more representative airway outcome measurement in patients with CF.
Keywords: cystic fibrosis; sputum induction; bronchoalveolar lavage

Correspondence to:
Dr M L Aitken, Division of Pulmonary and Critical Care

Medicine, Box 356522, 1959

NE Pacific Street, Room

BB1253, Seattle, WA @u.washington.edu

Returned to authors

21 September 2000
Received 16 June 2000

Revised version received

8 November 2000
Department of
Pediatrics, Division

Infectious Disease

Center, Seattle,

Washington, USA

\section{Pulmonary an \\ University of}

Washington, Seatte

M R Tonton, 
Like asthma, cystic fibrosis (CF) is characterised by airway inflammation. ${ }^{17}$ Although many patients with CF spontaneously expectorate sputum, many others do not, particularly early in the course of the disease. Fibreoptic bronchoscopy with bronchoalveolar lavage (BAL) has been used frequently as a research tool for evaluating airway contents in patients with CF, especially in those subjects who are symptom free and do not expectorate sputum. ${ }^{17}$ The possible advantages of SI as a research tool in this population are similar to those in asthmatic subjects-it is direct, non-invasive, inexpensive, and easy to do repeatedly. It might also serve as a research tool to study patients with $\mathrm{CF}$ who are unable to expectorate sputum spontaneously, including young children. This study compares SI with BAL and ES as a method for studying airway inflammation in subjects with CF. We have also compared SI with ES and BAL for the recovery of bacterial and fungal pathogens.

\section{Methods}

SUBJECTS

Subjects were recruited from the CF clinics at the University of Washington Medical Center and the Children's Hospital and Regional Medical Center, Seattle, WA, USA. All subjects were over 18 years of age and gave written informed consent to the study which was approved by the Human Subjects Committees of the University of Washington. Subjects had initial forced expiratory volume in one second $\left(\mathrm{FEV}_{1}\right)$ of $>50 \%$ predicted and were clinically stable. They remained on their usual medications, including any long term antibiotics, during the study period.

\section{STUDY DESIGN}

All subjects underwent bronchoscopy and sputum induction on separate days within a seven day period. The procedure order alternated from subject to subject. ES was randomly collected before either bronchoscopy or SI.

MEASUREMENT OF PULMONARY FUNCTION On the day of sputum induction, spirometric parameters were measured at baseline, 10 minutes after inhalation of $180 \mu \mathrm{g}$ albuterol but before SI, and 5 minutes after the completion of SI using a Cybermedic spirometer (Cybermedic Inc, Boulder, CO, USA) according to American Thoracic Society (ATS) guidelines. ${ }^{18}$

\section{FIBREOPTIC BRONCHOSCOPY}

Subjects fasted for a minimum of 4 hours before the procedure. Viscous lidocaine and cocaine $4 \%$ solution were used to anaesthetise the nasal septum. Conscious sedation was achieved with intravenous midazolam 1-4 mg and fentanyl 25-100 $\mu \mathrm{g}$. Lidocaine hydrochloride $2 \%$ solution was used for local anaesthesia of the airways. Flexible bronchoscopy was performed with a fibreoptic bronchoscope (Pentax FB-15H, Pentax FB-19H, or Olympus BF P20D). A transnasal approach was used in eight subjects and a transoral approach was used in two subjects with nasal polyposis. During bronchoscopy no suction was applied until the tip of the bronchoscope was below the vocal cords. The bronchoscope tip was directed immediately to the right upper lobe and wedged into a subsegment. The right upper lobe was selected for sampling because this area is usually the most radiographically involved in $\mathrm{CF} .{ }^{19} \mathrm{BAL}$ was performed by instillation of two $30 \mathrm{ml}$ aliquots of sterile nonbacteriostatic saline and recovered using wall suction $180 \mathrm{~mm} \mathrm{Hg}$ into a sterile $70 \mathrm{ml}$ specimen trap. Small volume BAL was performed in an attempt to optimise airway, rather than alveolar, sampling.

SPUTUM INDUCTION

Subjects were premedicated with albuterol $180 \mu \mathrm{g}$ via metered dose inhaler prior to the SI procedure. Using the protocol described by Fahy et $a l,{ }^{20}$ subjects inhaled nebulised sterile hypertonic saline $(3 \%)$ solution for 12 minutes from an Ultra-Neb 99 ultrasonic nebuliser (DeVilbiss, Somerset, PA, USA). This nebuliser generates particles of a mean mass median diameter of $4.5 \mu \mathrm{m}$ and has an output of $2.4 \mathrm{ml} / \mathrm{min}$. After expelling saliva, subjects were encouraged to cough at 2 minute intervals. The sputum was collected in a sterile plastic container for further processing.

\section{EXPECTORATED SPUTUM (ES)}

ES was collected immediately before, but on the same day as either the BAL or SI procedures. Subjects were asked spontaneously to expectorate into a sterile plastic collection container. All sputum produced over a 10-15 minute period was collected.

SAMPLE PROCESSING

All specimens were processed within 30 minutes of collection. Expectorated and induced sputum samples were processed in the same manner. The volume of sputum collected was measured and an equal volume of DTT $0.1 \%$ (Sputolysin; Behring Diagnostics Inc, Somerville, NJ, USA) was added. The sample was then mixed gently by vortex mixer and placed in a shaking water bath at $37^{\circ} \mathrm{C}$ for 15 minutes. Periodically, the samples were removed from the water bath for further brief gentle mixing with a plastic transfer pipette to ensure visible homogenisation; $1 \mathrm{ml}$ was removed for quantitative culture. The homogenised sputum sample was used to determine the total cell count and cytospins were prepared and stained (Hema 3, Fisher Scientific, Santa Clara, CA, USA). The remainder of the homogenised sputum was centrifuged at $2000 \mathrm{rpm}$ for 5 minutes. The supernatants were aspirated and frozen at $-70^{\circ} \mathrm{C}$ for later analysis. Slides were batched and a blinded observer (MVP) counted 500 non-squamous epithelial cells and cell differentials per sputum preparation.

The volume of recovered BAL fluid was measured and then centrifuged at $2000 \mathrm{rpm}$ for 5 minutes. The BAL supernatant was aspirated and frozen at $-70^{\circ} \mathrm{C}$ for later analysis. The cell pellet was resuspended in $2.5 \mathrm{ml}$ normal saline and an equal volume of DTT $0.1 \%$ (Sputolysin) was added. The sample was then 
mixed in the same manner as the sputum to ensure visible homogenisation and $1 \mathrm{ml}$ was removed for quantitative culture; $1 \mathrm{ml}$ was also removed for total and differential cell counting. Slides for cell counts were prepared, stained, and examined as above.

QUANTITATIVE CULTURE

Quantitative microbiology was performed as previously described. ${ }^{21}$ The $1 \mathrm{ml}$ aliquots removed for microbiological culture were plated within 2 hours of addition of DTT. Solubilised samples were serially diluted and plated directly onto the following media: MacConkey, OFPBL, DNase, streptococcal selective, mannitol salt, Haemophilus selective, and Mycosel agars. The MacConkey, DNA, and Mannitol salt plates were incubated in a $35^{\circ} \mathrm{C}$ ambient air incubator for 48 hours and the OFPBL plates were incubated in a $35^{\circ} \mathrm{C}$ ambient air incubator for 72 hours. Selective streptococcal and Haemophilus agar plates were incubated anaerobically at $35^{\circ} \mathrm{C}$ for 48 hours. Mycosel plates were incubated in a $30^{\circ} \mathrm{C}$ ambient air incubator for 5 days. Colony forming units per gram of sample were determined by counting the number of bacterial colonies of each organism growing on the selective media. The organisms were identified by standard biochemical tests. ${ }^{22}$

CYTOKINE DETERMINATION

IL- 8 and $\mathrm{TNF} \alpha$ were measured using a quantitative "sandwich" enzyme immunoassay technique (Quantikine, R\&D Systems, Minneapolis, MN, USA). Samples were run in triplicate and compared with a standard curve.

UREA DETERMINATION

There was enough remaining sample in eight of the 10 patients to determine urea concentrations in all three samples. Using the assumption that ES was an undiluted sample and that both SI and BAL samples were diluted, the correction factor varied from 0.6 to 2.5 .

\section{SUBJECT PREFERENCE}

At the completion of the study subjects were asked which of the two procedures, bronchoscopy or SI, they preferred. The same investigator $(\mathrm{NRH})$ asked all subjects.

DATA ANALYSIS

An ANOVA was performed for the following end points: sample volume, total and differential cell counts, and cytokine concentrations. Test specific detection rates were calculated for each method of sputum sampling based on pathogen recovery. A $\chi^{2}$ test was used to compare proportions of overall pathogen detection. For each organism recovered kappa statistics were calculated to examine the extent of agreement beyond that which would be expected on the basis of chance alone. ${ }^{23}$ Kappa $(\kappa)$ values of 0 were considered to represent chance agreement while values of 1 represent perfect agreement.

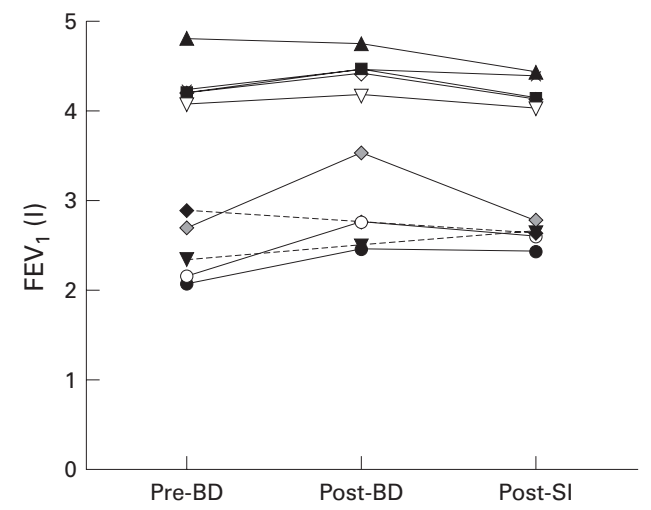

Figure 1 Initial $F E V_{1}$ for each subject (pre-BD), 10 minutes after $180 \mu \mathrm{g}$ albuterol but before the sputum induction (SI) procedure (post-BD), and 5 minutes after the SI procedure (post-SI). Each symbol and line represents an individual subject at each time point. Dotted lines represent two subjects in whom the post bronchodilator response data were missing. The post-SI FEV data point is missing for one subject.

\section{Results}

DEMOGRAPHIC AND SAFETY PROFILE

Eleven subjects entered the study. One subject did not complete the study because of a severe vasovagal event associated with insertion of an intravenous line. No other adverse events occurred and there were no significant changes in forced expiratory volume in one second $\left(\mathrm{FEV}_{1}\right)$ before and after the SI procedure (fig 1). Ten subjects (8 men) completed the study. Their mean age was 27 years (range 19-38, median 28) and the mean (SE) baseline $\mathrm{FEV}_{1}$ was $3.38(0.29) 1 / \mathrm{min}$. Four subjects were prescribed rhDNase, one of whom was also on inhaled tobramycin and oral doxycyline. Three subjects were taking a single oral antibioticeither ciprofloxacin, amoxicillin/clavulanic acid, or cephalexin.

Following bronchoscopy all patients were monitored with blood pressure, pulse oximetry, and continuous ECG tracing for 30 minutes. No adverse events occurred in that time interval. Moreover, no patient telephoned the investigators with an acute pulmonary exacerbation or pneumonia in the month following the procedure.

All subjects preferred SI to bronchoscopy. Three patients reported symptomatic improvement after SI.

\section{SAMPLE VOLUMES}

The mean (SE) sample volume collected by each method was $1.85(0.33) \mathrm{ml}$ for ES, 6.74 (1.46) $\mathrm{ml}$ for SI, and 17.65 (2.18) $\mathrm{ml}$ for BAL. Compared with ES, SI always gave larger volumes of sputum $(p=0.005)$. Two subjects spontaneously expectorated less than $1 \mathrm{ml}$ of sputum.

TOTAL AND DIFFERENTIAL CELL COUNTS

The mean (SE) total cell counts/ml sample collected were $6.17(1.66) \times 10^{6}$ for ES, 8.00 $(3.34) \times 10^{6}$ for SI, and $4.81(1.86) \times 10^{6}$ for BAL (fig 2A) There was no significant difference in the total number of cells $/ \mathrm{ml}$ of sample collected ( $p>0.05$ for all comparisons). There was a difference in the non-epithelial, 

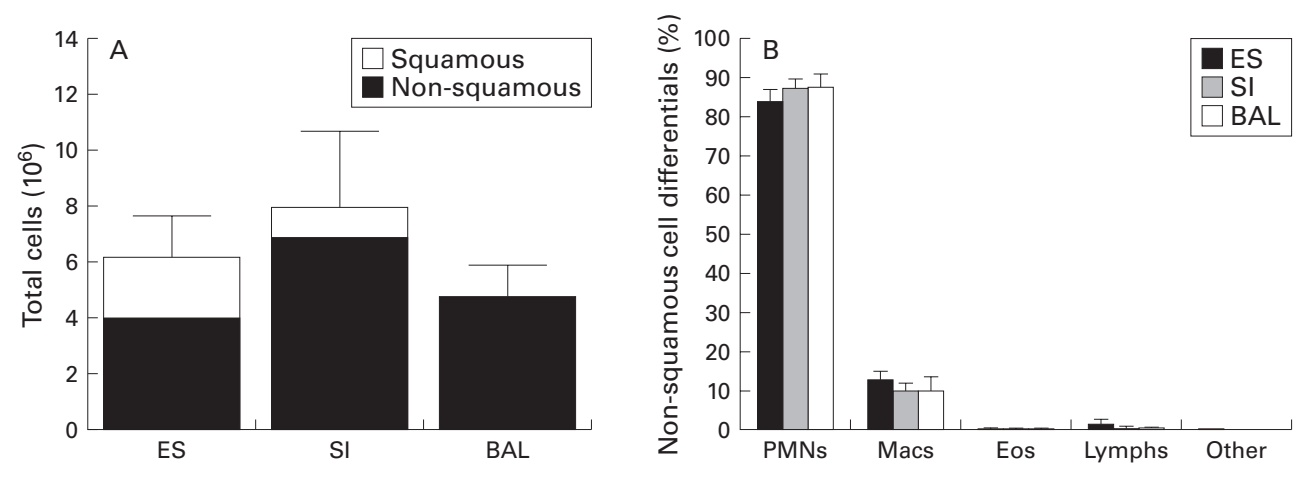

Figure 2 (A) Total cell counts per ml of original sample. There was no significant difference in the number of cells per ml of sample collected ( $p>0.05$ for all comparisons). The percentage of non-epithelial, non-squamous cells was different between expectorated sputum (ES) and both sputum induction (SI) and bronchoalveolar lavage (BAL; $p=0.03$ and $p=0.006$, respectively). (B) Differential counts of non-squamous cells. The cell populations were similar with each of the three sampling procedures.

Table 1 Test specific detection rates * for culture of ES, SI, and $B A L$

\begin{tabular}{llll}
\hline Organism & $E S$ & $S I$ & $B A L$ \\
\hline $\begin{array}{l}\text { P aeruginosa } \\
\text { mucoid }\end{array}$ & $6 / 6$ & $6 / 6$ & $6 / 6$ \\
$\begin{array}{l}\text { P aeruginosa } \\
\text { non-mucoid }\end{array}$ & $1 / 4$ & $3 / 4$ & $2 / 4$ \\
B cepacia & $1 / 1$ & $1 / 1$ & $1 / 1$ \\
S maltophilia & $3 / 4$ & $3 / 4$ & $2 / 4$ \\
A xylosoxidans & $1 / 2$ & $1 / 2$ & $0 / 2$ \\
H influenzae & $2 / 3$ & $1 / 3$ & $1 / 3$ \\
S aureus & $7 / 7$ & $6 / 7$ & $7 / 7$ \\
Aspergillus & $4 / 6$ & $5 / 6$ & $5 / 6$ \\
Overall sensitivity & $25 / 33(76 \%)$ & $26 / 33(79 \%)$ & $24 / 33(73 \%)$ \\
\end{tabular}

ES = expectorated sputum; $\mathrm{SI}=$ sputum induction; $\mathrm{BAL}=$ bronchoalveolar lavage.

^Number positive by specified test/number positive by any test.

non-squamous cells with mean (SD) percentages being $67(28) \%, 86(21) \%$, and 99 (1)\%of the total count for ES, SI, and BAL, respectively. These percentage counts were different between ES and both SI and BAL ( $p=0.03$ and $\mathrm{p}=0.006$, respectively), but were not different between SI and BAL $(\mathrm{p}=0.07)$. Cell differential counts (excluding squamous cells) by all collection methods were similar (84 (9)\%, 87 (7) $\%$ and 88 (11)\% polymorphonuclear cells for ES, SI, and BAL, respectively; fig $2 \mathrm{~B}$ ). The cell populations were similar with each of the three sampling procedures.

MICROBIOLOGY

The presence and quantitation of a specific set of organisms was compared between SI, ES, and BAL. Mucoid and non-mucoid Pseudomonas aeruginosa, Staphylococcus aureus, Burkholderia cepacia, Stenotrophomonas maltophilia, Achromobacter (formerly Alcaligenes) xylosoxidans, Haemophilus influenzae, and Aspergillus were selected because of their presumed

Table 2 Quantification of colony counts from ES and BAL fluid compared with SI

\begin{tabular}{llllll}
\hline & $\pm 1 \log _{10}$ & $\pm 2 \log _{10}$ & $\pm 3 \log _{10}$ & $\pm 4 \log _{10}$ & $\geqslant 5 \log _{10}$ \\
\hline Expectorated sputum & & & & & \\
$\quad$ aeruginos mucoid $(\mathrm{n}=7)$ & 5 & 1 & 1 & 0 & 0 \\
S aureus $(\mathrm{n}=6)$ & 4 & 0 & 2 & 0 & 0 \\
B cepacia $(\mathrm{n}=2)$ & 2 & 0 & 0 & 0 & 0 \\
$\quad$ maltophilia $(\mathrm{n}=1)$ & 1 & 0 & 0 & 0 & 0 \\
BAL fluid & 4 & 0 & 1 & 1 & 0 \\
$\quad$ Paeruginos mucoid $(\mathrm{n}=6)$ & 3 & 0 & 0 & 1 & 1 \\
S aureus $(\mathrm{n}=5)$ & 1 & 0 & 0 & 0 & 0 \\
B cepacia $(\mathrm{n}=1)$ & & &
\end{tabular}

ES = expectorated sputum; BAL = bronchoalveolar lavage; $\mathrm{SI}=$ sputum induction. $\star$ In $8 / 10$ patients a urea dilution correction was performed. relevance in CF lung infection, based in part on their inclusion in the Cystic Fibrosis Foundation Patient Registry. ${ }^{24}$ The test specific detection rate for each of the three methods (SI, ES, and BAL) was determined using the presence of any of the three cultures as an indicator of the presence of disease (table 1). The test specific detection rate of SI culture was $79 \%$ compared with $76 \%$ for ES and $73 \%$ for BAL ( $p=$ 0.68 ). Between the three methods of sample collection, cultures showed the following: perfect agreement $(\kappa=1)$ for recovery of mucoid $P$ aeruginosa and $B$ cepacia; high agreement $(\kappa=0.6-1)$ for recovery of $S$ aureus and Aspergillus; moderate to high agreement ( $\kappa=$ 0.4-0.7) for recovery of non-mucoid $P$ aeruginosa and $S$ maltophilia with the exception of SI $v$ BAL where there was low agreement $(\kappa=$ $0.2)$. A xylosoxidans was detected in one subject by ES alone and in one subject by SI alone. $H$ influenzae was detected in one subject by ES alone, in one subject by BAL alone, and in three subjects by SI and ES but not BAL. Organisms isolated from SI culture that were missed by either or both ES or BAL cultures included $S$ maltophilia, non-mucoid $P$ aeruginosa, and Aspergillus, each in a single patient.

Quantitation of organisms in each sample was also compared (table 2). A urea dilution factor was made in eight of the 10 patients in whom there was enough sample to measure urea concentrations in each sample. Colony counts ranged from $6.0 \times 10^{1}$ to $1.1 \times 10^{8} \mathrm{cfu} / \mathrm{g}$ specimen. For mucoid $P$ aeruginosa, $B$ cepacia, and $S$ maltophilia, the majority of SI cultures were within one $\log _{10}$ of the ES cultures. Comparing SI with BAL, the colony counts of mucoid $P$ aeruginosa and $S$ aureus in SI cultures were within one $\log _{10}$ in seven of the 11 specimens. For the other pathogens the BAL specimen had lower colony counts than the SI specimen. In the four instances in which organisms were detected on SI but not BAL, colony counts were $\leqslant 10^{4}$, and $<100$ in two of those instances.

\section{INFLAMMATORY MEDIATORS}

Two mediators of airway inflammation in CF were evaluated. IL-8 was detected in all subjects and in all samples. The concentrations with and without urea dilution correction are 
Table 3 Cytokine concentrations in expectorated sputum (ES), induced sputum (SI), and bronchoalveolar lavage (BAL) fluid

\begin{tabular}{llll}
\hline & ES & SI & BAL fluid \\
\hline IL-8 $(\mathrm{ng} / \mathrm{ml})$ & $18.0(12.2)$ & $12.8(7.5)$ & $4.0(3.0)^{\star}$ \\
Urea corrected IL-8 $(\mathrm{ng} / \mathrm{ml})(\mathrm{n}=8)$ & $13.4(11.0)$ & $13.5(7.1)$ & $13.9(17.9)$ \\
TNF $\alpha(\mathrm{pg} / \mathrm{ml})$ & $102(101)^{\star}$ & $45(27)$ & $18(19)$ \\
Urea corrected TNF $\alpha(\mathrm{pg} / \mathrm{ml})(\mathrm{n}=8)$ & $80(71)$ & $42(42)$ & $43(42)$
\end{tabular}

There was a difference in IL- 8 concentration in SI from that in ES and BAL $(p=0.01$ and $p=0.03$, respectively). When a dilution correction was made these differences were no longer seen. There was a difference in TNF $\alpha$ concentration between SI and ES $(p=0.03)$ but this was no longer seen when corrected for dilution.

shown in table 3 . Without urea correction IL-8 $(\mathrm{ng} / \mathrm{ml})$ was lower in BAL fluid than in either ES or SI $(p<0.05)$. TNF $\alpha$ was also detected in the three sample types. Concentrations of $\mathrm{TNF} \alpha$ in SI were significantly greater than in BAL fluid $(\mathrm{p}=0.03)$, but again there was no difference when a urea dilution correction was made. Urea corrected $\mathrm{TNF} \alpha$ concentrations in BAL fluid and ES remained different $(p=0.01)$.

\section{Discussion}

SI was well tolerated and preferred to BAL by all subjects. SI resulted in larger sample volumes than ES, a higher percentage of non-squamous cells than ES, higher colony counts, and tended toward higher detection rates for $\mathrm{CF}$ specific pathogens. Concentrations of the cytokines IL- 8 and $\mathrm{TNF} \alpha$ when corrected for dilution were the same.

Induction of sputum with hypertonic saline has been shown to be safe in patients with moderate to severe asthma and was associated with no adverse events in our 10 subjects with CF. In fact, three subjects reported feeling better after the procedure. Clinical improvement may be the result of an effect on airway clearance, consistent with results from a recent 2 week clinical trial of nebulised saline in $\mathrm{CF}^{25}$ Hypertonic saline with cough has been shown to enhance mucociliary clearance significantly. ${ }^{26}$ Administration of a $\beta_{2}$ agonist prior to SI was done for safety, but it too may have had a therapeutic effect and contributed to the subjects' sense of improvement after SI. Neither the concentration of hypertonic saline nor pretreatment with $\beta_{2}$ agonists alters the differential cell counts in induced sputum. ${ }^{27}$

In contrast to ES, all subjects undergoing SI produced sample volumes of more than $1 \mathrm{ml}$, the minimum volume often necessary to perform routine assays and reproducible cell counts. Less squamous cell contamination occurred in the SI samples than in ES. Previous studies have shown that the method of processing CF sputum affects cell counts, often erroneously lowering counts because of poor cell dispersal. ${ }^{28}$ We used DTT to process our samples so that our results could be more easily compared with studies using SI in subjects with asthma; however, even higher cell counts may be achieved with methods such as enzymatic digestion. ${ }^{28}$ The populations of nonsquamous cells seen in the cell differential counts were the same for SI, ES, and BAL, suggesting that each method was sampling primarily airway populations.
The microbiological results demonstrated a potential advantage of SI culture over both ES and BAL. Overall, the sensitivity of isolation of organisms from SI culture was slightly (although not statistically) better than both ES and BAL. SI missed a single isolation of $S$ aureus, but otherwise performed better overall than the traditional "gold standard" for lower airway culture, BAL. In addition, SI recovered higher colony counts, a benefit that could be an advantage in the research setting.

In children with chronic pulmonary infection oropharyngeal suction has been used to identify respiratory tract pathogens with a sensitivity of $89 \%$ compared with BAL ${ }^{29}$ Since SI tended to be more sensitive than BAL for detecting CF respiratory pathogens, it may be useful both as a research tool and as a clinical method for identifying respiratory pathogens in CF.

Inflammatory mediators were found in concentrations equivalent to or greater than those previously reported in patients with $\mathrm{CF}^{30}$ The presence of hypertonic saline may increase the amount of $\mathrm{Na}^{+}$and $\mathrm{Cl}^{-}$in airway surface liquid and rehydrate the periciliary fluid. ${ }^{31}$ Hyperosmolarity has been shown to stimulate IL-8 production in human bronchial epithelial cells in vitro. ${ }^{32}$ However, we doubt that a 12 minute exposure to hypertonic saline in vivo would allow adequate time to increase intracellular IL-8 production.

Limitations of this preliminary study are that it did not look at cell viability or reproducibility of results in any given subject. Both of these outcomes ${ }^{5}$ have been looked at in normal subjects, ${ }^{11}$ asthmatic patients, ${ }^{72}$ and those with COPD. ${ }^{6}$ In other patient populations it has been shown that cell viability is enhanced with SI compared with ES, and that results from SI in these populations are reproducible.

Sputum induction has become a well validated research tool for evaluating a variety of indices of inflammation, both cellular and humoral, in non-CF diseases of the airways such as asthma. This study shows that SI is well tolerated and provides valid information regarding the markers of inflammation and the microbiology of the airways in subjects with CF. As a research tool, SI offers many advantages over bronchoscopy or the collection of spontaneously expectorated sputum. Compared with bronchoscopy, SI could obviate the need for multiple invasive procedures in appropriately chosen longitudinal studies, it is inexpensive, and is preferred by patients. Compared with BAL, the disadvantages of SI are that sequential sampling of the same subsegmental airway is not possible and the technique cannot be taught to very young children. Improving upon expectorated sputum, subjects can be well at the time of study and potential subjects, including children, who do not spontaneously expectorate need not be excluded from research protocols. Sputum induction therefore represents an alternative to standard methods of sampling the airways in patients with CF, with potential value in both the research and clinical setting. 
Supported by a grant from the Firland Sheltered Workshop.

1 European Respiratory Society Task Force. Methods for assessment of airways inflammation (Jeffery PK, Bousquet assessment of airways inflammation (Je

2 Pin I, Freitag AP, O'Byrne PM, et al. Changes in the cellular profile of induced sputum after allergen-induced asthmatic profile of induced sputum after allergen-induced
responses. Am Rev Respir Dis 1992;145:1265-9.

3 responses. Am Rev Respir Dis 1992;145:1265-9. interleukin-8 and tumor necrosis factor- $\alpha$ in induced disease or asthma. Am $\mathcal{F}$ Respir Crit Care Med 1996;153: $530-4$

4 Fahy JV, Fleming HE, Wong HH, et al. The effect of an antiIgE monoclonal antibody on the early- and late-phase responses to allergen inhalation in asthmatic subjects. $A m \mathcal{F}$ Respir Crit Care Med 1997;155:1828-34.

5 Fabbri LM, Durham S, Holgate ST, et al. Assessment of airway inflammation: an overview. Eur Respir f 1998;11(Suppl 26):6-8s.

6 Bhowmik A, Seemungal TA, Sapsford RH, et al. Comparison of spontaneous and induced sputum for investigation of airway inflammation in chronic obstructive pulmonary disease. Thorax 1998;53:953-6.

7 Pizzichini MMM, Popov TA, Efthimiadis A, et al. Spontaneous and induced sputum to measure indices of airway inflammation in asthma. Am $\mathcal{f}$ Respir Crit Care Med 1996;154:866-9.

8 Kips JC, Fahy JV, Hargreave FE, et al. Methods for sputum induction and analysis of induced sputum method for assessing airway inflammation in asthma. Eur Respir $\mathcal{F}$ 1998;11 (Suppl 26):9-12s.

9 Gershman NH, Liu H, Wong HH, et al. Fractional analysis of sequential induced sputum samples during sputum induction: evidence that different lung compartments are sampled at different time points. $\mathcal{F}$ Allergy Clin Immunol 1999;104:322-8.

10 Pizzichini E, Pizzichini MM, Efthimiadis A, et al. Measurement of inflammatory indices in induced sputum: effects of selection of sputum to minimize salivary contamination. Eur Respir f 1996;9:1174-80.

11 Fahy JV, Liu J, Wong H, et al. Cellular and biochemical analysis of induced sputum from healthy and asthmatic analysis of induced sputum from healthy and

12 Pizzichini E, Pizzichini MMM, Efthmimiadis A, et al. Indices of airway inflammation in induced sputum: reproducibility and validity of cell and fluid phase meas

13 Gibson PG, Gabardo AG, Morris MM, et al. Cellular characteristics of sputum from patients with asthma and chronic bronchitis. Thorax 1989;44:693-9.

14 Pin I, Gibson PG, Kolendowicz R, et al. Use of induced sputum cell counts to investigate airway inflammation in asthma. Thorax 1992;47:25-9.

15 Efthimiadis A, Pizzichini MMM, Pizzichini E, et al. The influence of cell viability and squamous epithelial cell contamination on the reliability of sputum differential cell counts. Am 7 Respir Crit Care Med 1995;151: A384.
16 Virchow JC, Holscher U, Virchow C. Sputum ECP levels correlate with parameters of airflow obstruction. Am Rev correlate with parameters of
Respir Dis 1992;146:604-6.

17 Konstan MW, Berger M. Current understanding of the inflammatory process in cystic fibrosis: onset and etiology. Pediatr Pulmonol 1997;24:137-42.

18 American Thoracic Society. Standardization of spirometry: 1987 update. Am Rev Respir Dis 1987;136:1285-98.

19 Greene KE, Takasugi JE, Godwin JD, et al. Radiographic changes in acute exacerbations of cystic fibrosis in adults: a pilot study. Am f Roentgenol 1994;163:557-62.

20 Fahy J, Liu J, Wong H, et al. Analysis of cellular and biochemical constituents of induced sputum after allergen challenge: a method for studying allergic airway inflammation. F Allergy Clin Immunol 1994;93:1031-9.

21 Burns JL, Emerson J, Stapp JR, et al. Microbiology of sputum from patients at cystic fibrosis centers in the United States. Clin Infect Dis 1998;27:158-63.

22 Shigei J. Test methods used in the identification of commonly isolated aerobic gram-negative bacteria. In: Isenberg HD, ed. Clinical microbiology procedures handbook. Washington, DC: American Society for Microbiology, 1992: 1.19-1-110.

23 Fleiss JL. Statistical methods for rates and proportions. 2nd ed. New York: John Wiley and Sons, 1981.

24 Cystic Fibrosis Foundation Patient Registry. Annual data report,

25 Eng PA, Morton J, Douglass JA, et al. Short-term efficacy of ultrasonically nebulized hypertonic saline in cystic fibrosis. ultrasonically nebulized hyperto

26 Robinson M, Regnis JA, Bailey DL, et al. Effect of hypertonic saline, amiloride, and cough on mucociliary clearance in patients with cystic fibrosis. Am F Respir Crit Care Med 1996;153:1503-9.

27 Popov TA, Pizzichini MMM, Pizzichini E, et al. Some technical factors influencing the induction of sputum for cell analysis. Eur Respir 7 1995;8:559-65.

28 Cai Y, Carty K, Gibson P, et al. Comparison of sputum processing techniques in cystic fibrosis. Pediatr Pulmonol 1996;22:402-7

29 Avital A, Uwyyed K, Picard E, et al. Sensitivity and specificity of oropharyngeal suction versus bronchoalveolar lavage in identifying respiratory tract pathogens in children with chronic pulmonary infection. Pediatr Pulmonol 1995;20:40-

30 Salva PS, Doyle NA, Graham L, et al. TNF $\alpha$, IL-8, soluble ICAM-1, and neutrophils in sputum of cystic fibrosis patients. Pediatr Pulmonol 1996;21:11-9.

31 Folkesson HG, Kheradmand F, Mathay M. The effect of saltwater on alveolar epithelial barrier function. Am f Respir Crit Care Med 1994;150:1555-63.

32 Hashimoto S, Matsumoto K, Gon Y, et al. Hyperosmolarity induced interleukin-8 expression in human bronchial epithelial cells through p38 mitogen-activated protein kinase. Am f Respir Crit Care Med 1999;159:634-40. 